\title{
Energy Enterprise Management in China under the Perspective of Green Development
}

\author{
Peng $\mathrm{He}^{1}$, LiXia Zeng ${ }^{2, *}$, and Jie $\mathrm{Dai}^{3}$ \\ ${ }^{1}$ College of Cultural Industries and Tourism, Xiamen University of Technology, China \\ ${ }^{2}$ College of Economics and Management, Xiamen University of Technology, China \\ ${ }^{3}$ Institute for Advanced Studies, University of Malaya, Malaysia
}

\begin{abstract}
With the aggravation of climate change, energy enterprises will gradually assume more and more responsibilities for environmental protection and energy conservation. How to incorporate green ideas into their business management has become an important theme. After reviewing the past background and policies, based on the supply chain model established in the past literature, this paper determines the more important indicators that affect the sustainable development of the company, and based on this, puts forward the points that should be paid attention to in the future management of the enterprise. First, energy companies should incorporate green ideas into their corporate training to raise the morale of their employees. Second, through strict control of upstream and downstream suppliers and the establishment of environmental requirements, so as to improve the green degree of the entire supply chain. Third, in the current society with advanced information technology, the operation of information means to achieve the goal of green management should be the focus of future management.
\end{abstract}

\section{Introduction}

The destructiveness of mining and the extensive production in the energy industry are the manifestation of the great waste of social public resources, which seriously violate the sustainable development strategy in China. For example, coal resource has always been one of the most important energy minerals in the world. It has the characteristics of large reserves, wide distribution, low price, large demand and high utilization rate. According to the latest statistics that can be collected, the proven recoverable reserves of coal resources in the world are 984.211 million tons, and coal resources still account for a certain proportion, up to $25 \%$, in the world's primary energy consumption. China's coal output has ranked first in the world for many years in a row. According to the data, coal production was 3.45 billion tons in 2017, while consumption was 3.08 billion tons, up $3.2 \%$ and $0.4 \%$ respectively from the previous year. The long-term importance of coal resources in energy consumption is also fully reflected in China. The peak of the apparent consumption of coal in China appeared in 2013, and it has significant and outstanding characteristics, which are mainly reflected in rich reserves, various types and high extraction rate. The destruction of various environmental resources leads to the extinction of many endangered species every year, and the destruction of human living space is increasingly intensified, such as the pollution of air resources and water resources, climate anomalies caused by the greenhouse effect and many other problems [1-3]. With the increasing public awareness of environmental protection, the importance of maintaining the stability of natural ecology has gradually come to be recognized around the world. At present, for the protection of the natural environment problem is more and more discussions and research, combining with our country the planning for the sustainable development of society, from promoting transformation and upgrading of industrial structure of China's traditional industries, improve industrial emissions standards, advocate green low carbon development concept to protect and repair of the natural ecological environment, to reduce pollution and damage to the environment at the same time, also has given rise to the emergence of many new environmental protection enterprises, and make the environmental protection enterprise got rapid development. However, in the field of energy, Chinese enterprises still have many problems to be solved, mainly in the two aspects of sustainability and clean production. For example, the development and application of green energy and the excess production capacity of traditional mineral resources and energy enterprises, it can be said that China's environmental governance and protection work is still facing many difficulties and challenges.

At present, various enterprises are giving new strategic adjustment, the most eye-catching part should be Sinopec's "green enterprise action plan". According to the plan, Sinopec will account for more than $50 \%$ of its clean energy production within six years. In terms of providing high-quality oil products, Sinopec has

\footnotetext{
* Corresponding author: 2011110102@xmut.edu.cn
} 
promoted the quality of gasoline and diesel oil from limiting impurity content to optimizing hydrocarbon components to a new stage, maintaining the international advanced level of oil quality. In October 2018, the entire factory VI standard automotive gasoline and diesel will reach countries, bunker fuel sulfur content in 2020 from $3.50 \%$ to $0.50 \%$, is expected to reduce sulfur dioxide emissions of 1.3 million tons/year. Thus, the era of low carbon economy is coming. Low-carbon economy is an economic form based on the concept of sustainable development, in which different ways such as technological innovation, institutional innovation, industrial development and energy development are utilized to minimize the consumption of coal, oil and other energy resources and reduce greenhouse gas emissions, so as to realize the common development of social benefits, economic benefits and ecological benefits. The development of low-carbon economy not only needs to clarify the responsibility of environmental protection and meet the national target requirements of energy conservation and consumption reduction, but also needs to adjust the economic structure system, improve the efficiency of energy utilization, fully develop new energy technologies and build a green ecological environment.

The essence of low-carbon economic development is the efficient use of energy, the development of new clean energy and the promotion of green GDP. The key is the development of energy technology, the improvement of energy consumption efficiency, the upgrading of industrial structure and the change of human survival concept. The development of low-carbon economy is an adjustment that human beings have to face under the increasingly harsh global environment. The development of clean energy and the low-carbon adjustment of economic structure will open up a new road of ecological civilization. For energy enterprises, it is more important to improve the low-carbon awareness, implement energy reduction at the source, create new economic growth points, and implement low-carbon economic development on the basis of ensuring the economic benefits of energy enterprises [4-8]. Starting from the supply and management of enterprises, this paper puts forward suggestions, hoping to reduce the waste of resources, effectively guarantee the sustainable development of energy enterprises, and reflect the fulfilment of corporate social responsibility

\section{Methodology}

\subsection{Policy process}

On December 20, 2016, the State Council issued the "much starker choices-and graver consequences-in" energy conservation and emissions reduction comprehensive work plan ", aimed at resolving our country because of industrialization, speed up the urbanization process and the consumption structure upgrade, lead to energy resources and environment problems brought by the sharp increase in demand, and ensure the realization of "much starker choices-and graver consequences-in planning outline" put forward the obligatory targets for energy conservation and emissions reduction. The work Plan makes a comprehensive plan for the national work on energy conservation and emission reduction during the 13th Five-Year Plan period, defines the main targets and key tasks for energy conservation and emission reduction, divides the national targets for energy conservation and emission reduction into various regions, and proposes specific measures for energy conservation and emission reduction [9-11]. It is a programmatic document guiding the national work on energy conservation and emission reduction. In order to greatly improve the efficiency of energy resources development and utilization, effectively control the total energy consumption, ensure a $15 \%$ reduction in energy consumption per unit of GDP during the 13th Five-Year Plan period, and limit the total energy consumption to 5 billion $\mathrm{t}$ standard coal by 2020, on December 23, 2016, the National Development and Reform Commission promulgated the action Plan for national Energy Conservation during the 13th Five-Year Plan Period. On January 11, 2017, the National Development and Reform Commission issued the Energy Conservation Standard System Construction Plan, which clearly stated: in the energy field, the focus should be on formulating technical standards related to clean and efficient use of coal, and strengthening the revision of standards on natural gas, new energy and renewable energy.

\subsection{Conceptual model}

Green supply chain management is an innovative way of environmental management. Based on the supply relationship between upstream and downstream enterprises, it takes core enterprises as the fulcrum and passes energy conservation and environmental protection requirements to upstream and downstream enterprises step by step through green supplier management, green procurement and other work, thus driving the continuous improvement of the green level of the whole industrial chain. Cao [4] consulted relevant materials such as green supplier selection method, green supplier evaluation index system, green supplier performance evaluation and books, journal papers and academic papers with corresponding keywords. The evaluation index system of green suppliers mainly focuses on the selection of product quality, purchase cost (product price), supplier service (delivery time), supplier enterprise capability (competitiveness) and green indicators. Therefore, based on the existing literature research results, the evaluation index system of coal enterprises' green suppliers was finally determined by visiting relevant personnel of coal enterprises and combining with the green supplier selection method. In this index system, five indicators, namely quality, cost, supplier capability, service and response level, and enterprise green innovation ability, are selected as the first-level indicators, and 21 indicators, such as quality certification system and product qualification rate, are used as the second-level 
indicators to evaluate green suppliers (As shown in Table 1).

Among them, the quality and cost in the first-level indicators ensure the quality and economic benefits of the supplier's products, the competence, service and response level of the supplier ensures the competitiveness of the supplier, and the green innovation ability of the enterprise reflects the effect of the supplier in environmental protection. On this basis, we delineate the degree of importance of each indicator to environmental sustainability, with * indicating weak importance, $* *$ medium importance and $* * *$ strong importance. Based on this, Suggestions for sustainable development of energy enterprise management are given.

Table 1. Conceptual model.

\begin{tabular}{|c|c|c|}
\hline $\begin{array}{l}\text { Indicator } \\
\text { Type }\end{array}$ & Evaluation Index & $\begin{array}{l}\text { Significant rate for } \\
\text { Sustainability }\end{array}$ \\
\hline \multirow{4}{*}{ Guality } & $\begin{array}{l}\text { Quality certification } \\
\text { system }\end{array}$ & $* *$ \\
\hline & Product percent of pass & *** \\
\hline & $\begin{array}{l}\text { Reliability of safety } \\
\text { protection device }\end{array}$ & $*$ \\
\hline & Product durability & $* * *$ \\
\hline \multirow{4}{*}{ Cost } & $\begin{array}{l}\text { Average product price } \\
\text { ratio }\end{array}$ & $*$ \\
\hline & Price rigidity & $*$ \\
\hline & Transport costs & $* *$ \\
\hline & $\begin{array}{l}\text { Discount rate of bulk } \\
\text { price }\end{array}$ & $*$ \\
\hline \multirow{4}{*}{$\begin{array}{l}\text { Power of } \\
\text { suppliers }\end{array}$} & Asset-liability ratio & $*$ \\
\hline & $\begin{array}{l}\text { Enterprise market } \\
\text { position }\end{array}$ & $* * *$ \\
\hline & $\mathrm{R} \& \mathrm{D}$ & **** \\
\hline & Technological level & $* * *$ \\
\hline \multirow{5}{*}{$\begin{array}{l}\text { Service and } \\
\text { response } \\
\text { levels }\end{array}$} & $\begin{array}{l}\text { Order processing } \\
\text { accuracy }\end{array}$ & $*$ \\
\hline & $\begin{array}{l}\text { Average order } \\
\text { completion rate }\end{array}$ & $*$ \\
\hline & On time delivery & $*$ \\
\hline & $\begin{array}{l}\text { After-sales service } \\
\text { level }\end{array}$ & $*$ \\
\hline & $\begin{array}{l}\text { Degree of enterprise } \\
\text { informatization }\end{array}$ & $* * *$ \\
\hline \multirow{4}{*}{$\begin{array}{l}\text { Enterprise } \\
\text { green } \\
\text { innovation } \\
\text { ability }\end{array}$} & $\begin{array}{l}\text { Enterprise green } \\
\text { culture }\end{array}$ & $* * *$ \\
\hline & $\begin{array}{l}\text { Environmental } \\
\text { protection cost }\end{array}$ & $* * *$ \\
\hline & Product green design & $* * *$ \\
\hline & $\begin{array}{l}\text { Three waste discharge } \\
\text { ratio }\end{array}$ & $* * *$ \\
\hline
\end{tabular}

\section{Policy suggestions}

\subsection{Internal culture management of energy enterprises}

In the field of energy, it is unrealistic to promote and realize the green management mode of enterprises in a short period of time. Only by implementing the green management system in various energy enterprises based on the actual market and promoting the sustainable development of social economy and ecological economy can the goal of harmonious coexistence between man and nature be achieved. First of all, enterprise management personnel as to promote the dominant force of green enterprise management must first fully set up the consciousness of green management. Green consciousness of the management in the process of pushing energy enterprise implement green management will produce important influence, both from the ecological environment and the enterprise management efficiency will reveal the decisive role. Therefore, in order to implement the green management of energy enterprises, enterprise management should adhere to the concept of sustainable development, deepen the awareness of green ecology and management, and strictly abide by the environmental laws and regulations to formulate scientific and reasonable. The green management measures in line with the actual development needs of enterprises can help energy enterprises meet the requirements of high efficiency, low consumption and low emission in the actual production process, and promote energy enterprises to give play to positive social, economic and ecological benefits. Secondly, from top to bottom, the management of the enterprise should carry out general training on the environmental protection awareness of the grass-roots employees, strengthens the green and ecological concept of the employees of the energy enterprise, and makes a specific green work standard for multiple links from procurement, production to sales according to the characteristics of the employees' positions. The concept of green development should be rooted in every worker of the energy enterprise, so that every employee can put into work with the awareness of environmental protection and low carbon. Meanwhile, a scientific and strict reward and punishment system should be set up to enhance the enthusiasm of staff to practice green and low emission production.

\subsection{Green supply management of energy}

To reduce emissions and reduce ecological pressure, we can improve the energy efficiency of traditional fossil fuels and increase the proportion of clean energy. At present, traditional fossil fuels have a certain advantage over wind energy, solar energy and other environmentfriendly new energy sources in the cost of energy use. Most companies choose to use more traditional fossil fuels as their main energy sources from the economic perspective. From the perspective of the stock and distribution of mineral resources in China, combined with the needs of rapid industrial development, it is also in line with the law of phased development that most enterprises still take coal as the main fossil fuel, and there are still many problems to break through this energy supply mode in a short time. Key energy enterprises will promote the transformation of traditional mineral energy to greener energy, such as natural gas, solar energy, wind energy and hydrogen energy, and increase the proportion of clean energy in the energy application field by building an environmental protection 
supply system and achieve green and low-carbon goals by reducing emissions from conventional energy sources. At the same time, due to the production technology and environmental factors in the production process of traditional fossil fuels, strict product quality acceptance procedures should be carried out for the products provided by equipment and raw material suppliers in order to stabilize the production capacity and production safety of enterprises. Record suppliers whose product quality is unstable or whose process level is below production standard and strictly limit their eligibility to participate in product supply should be done. In order to guarantee the long-term quality of supply, enterprises should give a priority to the quality of suppliers. Only by establishing a strict supplier management mechanism can suppliers compete with each other in terms of product quality, supply speed and service level, so as to ensure that energy enterprises can take the initiative in the development process.

\subsection{Energy enterprises to carry out information management}

Under the social background of rapid development of science and technology, many manufacturing enterprises choose to introduce visual management platform to enhance their competitiveness in the supply market. Therefore, from the perspective of improving the energy efficiency of traditional energy enterprises, it is also in line with the trend of the development of the times. The introduction of information management mode is a necessary means to improve the management efficiency of energy enterprises and implement green management. The introduction of information management system will play a more scientific and efficient role in recording supplier information and product details in the procurement process of energy enterprises. Information management platform can not only record detailed information of suppliers in the management process, but also facilitate energy enterprises to evaluate each supplier, make more efficient analogy selection for product quality and price, and establish supplier access standards based on this.

\section{Conclusion}

With the aggravation of climate change, energy enterprises will gradually assume more and more responsibilities for environmental protection and energy conservation. How to incorporate green ideas into their business management has become an important theme. After reviewing the past background and policies, based on the supply chain model established in the past literature, this paper determines the more important indicators that affect the sustainable development of the company, and based on this, puts forward the points that should be paid attention to in the future management of the enterprise.

First, energy companies should incorporate green ideas into their corporate training to raise the morale of their employees. Second, through strict control of upstream and downstream suppliers and the establishment of environmental requirements, so as to improve the green degree of the entire supply chain. Third, in the current society with advanced information technology, the operation of information means to achieve the goal of green management should be the focus of future management.

\section{References}

1. R. Walz. Development of environmental indicator systems: experiences from Germany. Environ. Manage., 25, 6(2000)

2. M. Epstein. Improving environmental management with full environmental cost accounting. Environ. Quality Manage., 6, 1 (1996)

3. P. Letmathe, R. Doost. Environmental cost accounting and auditing. Managerial Auditing J., 15 , 8 (2000)

4. Y. Cao. Research on green Supplier selection of coal enterprises. J. Henan Polytechnic University, 4, 4 (2020)

5. R. Xu, L. Chou, W. Zhang. The effect of $\mathrm{CO} 2$ emissions and economic performance on hydrogenbased renewable production in 35 European countries, Int. J. Hydrogen Energy, 44, 56 (2019) Ј

6. L. Chou, W. Zhang, M. Wang, F. Yang. The influence of democracy on emissions and energy efficiency in America : new evidence from quantile regression analysis, Environment and Energy, 31, 8 (2020).

7. H. Lin, L. Chou, W. Zhang. Cross-Strait climate change and agricultural product loss. Environ. Sci. Pollut. Res., 27, 12 (2019)

8. X. Pan, W. Zhang, L. Chou. The theory on the environmental emission trading under the concept of two-tired earning, EKOLOJI, 28, 107 (2019)

9. G. Lakshmi, S. Tilley. The power of community renewable energy enterprises: The case of Sustainable Hockerton Ltd. Energy Policy, 129, 129 (2019)

10. C. You, X. Xu. Coal combustion and its pollution control in China. Energy, 35, 11 (2010)

11. X. Xie, H. Ai, Z. Deng. Impacts of the scattered coal consumption on PM2. 5 pollution in China. $J$. Cleaner Prod., 245, 118922 (2020) 